\title{
Cardiovascular Risk Factors and Epicardial Adipose Tissue Measured by Chest Computed Tomography in Healthy Adults
}

\author{
Jongwoo Kim, Seon Yeong Lee* \\ Department of Family Medicine, Inje University Sanggye-Paik Hospital, Seoul, South Korea \\ Email: *sylee@paik.ac.kr
}

How to cite this paper: Kim, J. and Lee, S.Y. (2017) Cardiovascular Risk Factors and Epicardial Adipose Tissue Measured by Chest Computed Tomography in Healthy Adults. Journal of Biosciences and Medicines, 5, 41-50.

https://doi.org/10.4236/jbm.2017.511006

Received: October 23, 2017

Accepted: November 20, 2017

Published: November 23, 2017

Copyright $\odot 2017$ by authors and Scientific Research Publishing Inc. This work is licensed under the Creative Commons Attribution International License (CC BY 4.0).

http://creativecommons.org/licenses/by/4.0/

\section{(c) (i) Open Access}

\begin{abstract}
Background: Epicardial adipose tissue (EAT) may produce several cytokines contributed to coronary atherosclerosis. EAT was measured by transthoracic echocardiography or 3 dimensional cardiac computed tomography (CT) on previous studies. We aimed to evaluate the correlation between EAT thickness and cardiovascular risk factors in healthy adults. Method: We collected clinical, biochemical information from 469 subjects ( 371 men and 98 women) who visited our health promotion center. EAT thickness was measured by chest CT on the free wall of the right ventricle. Result: The mean EAT thickness was $2.47 \pm 1.64 \mathrm{~mm}$ in total of 469 subjects. EAT thickness was significantly correlated to age, weight, body mass index (BMI), total body fat, systolic and diastolic blood pressure, total cholesterol, low density lipoprotein (LDL)-cholesterol, and fasting glucose in men and to age, height, weight, BMI, total body fat, systolic and diastolic blood pressure, triglycerides, C-reactive protein (CRP), and fasting glucose in women. Multivariate analysis showed that age, $\mathrm{BMI}$, systolic blood pressure, fasting glucose were the variables that independently correlated to EAT thickness in men. But there was no significant independent variable in women. Conclusion: In our study, EAT thickness measured with chest $\mathrm{CT}$ in healthy individuals correlates with cardiovascular risk factors in men.
\end{abstract}

\section{Keywords}

Epicardial Adipose Tissue, Cardiovascular Risk Factor, Visceral Fat, Chest Computed Tomography

\section{Introduction}

Obesity is an important risk factor for cardiovascular and metabolic diseases, 
such as hypertension and diabetes [1] [2]. Visceral fat, defined as the amount of fat distributed around visceral organs, is strongly associated with the development of metabolic syndrome, the incidence of cardiovascular disease, and mortality [3] [4]. Therefore, accurate evaluation of visceral fat mass is very important for identifying patients at high risk of metabolic syndrome and cardiovascular disease. Epicardial adipose tissue, in addition to the measurement of visceral fat, has been studied as a new indicator for evaluation of visceral fat [5] [6] [7]. Epicardial adipose tissue fat is situated around the heart within the pericardium. It originates from the splanchnopleuric mesoderm, and its origin is thus the same as abdominal visceral fat. Epicardial adipose tissue fat is metabolically active and secretes various hormones and cytokines that affect vascular endothelial functions, which can play an important role in the development of coronary artery disease [8] [9]. However, studies on epicardial adipose tissue fat conducted to date have mainly involved non-healthy participants with suspected cardiovascular disease or chronic disease. In addition, in most previous studies, epicardial adipose tissue was measured using transthoracic echocardiography or 3-D cardiac computed tomography (CT). There are few studies using chest CT, which is relatively frequently performed in clinical practice. The present study aimed to measure epicardial adipose tissue using chest CT in healthy adults with no history of cardiovascular disease or chronic disease, and to investigate its correlation with cardiovascular disease risk factors.

\section{Materials and Methods}

\subsection{Participants}

We recruited and investigated all adults aged 20 years or older who underwent chest CT at Health Promotion Center, Sanggye-Paik Hospital in Seoul, South Korea from January 1, 2010 to December 31, 2010. Epicardial adipose tissue thickness was measured on the free wall of the right ventricle. Patients were excluded if the epicardial adipose tissue thickness could not be measured because the pericardium boundaries were unclear, if it was not easy to identify structures in the heart due to blurred images obtained with chest CT, or if they had a history of heart failure, renal failure, severe hepatic disease, malignant tumor, hypertension, diabetes, or coronary artery disease. Finally, 469 subjects ( 371 men and 98 women) who did not meet the exclusion criteria, were included in this analysis.

\subsection{Methods}

The height and weight of each participant was measured to $0.1 \mathrm{~cm}$ and $0.1 \mathrm{~kg}$, respectively, using the same scale with shoes taken off in an upright position. Body mass index (BMI) was calculated by dividing the body weight by the square of the height $\left(\mathrm{kg} / \mathrm{m}^{2}\right)$. Body fat was measured using X-scan plus II (Body Composition Analysis, Jawon Medical Co. Ltd., Korea). Blood pressure was measured as brachial artery blood pressure with an electronic automatic manometer (TM-2655P, A \& D Co. Ltd., Japan) while each participant was sitting on a 
chair in a stable state for more than 10 minutes.

All participants fasted for at least 8 hours before blood sampling. Venous blood was collected to measure serum total cholesterol, triglycerides, high density lipoprotein (HDL) cholesterol, low density lipoprotein (LDL) cholesterol, C-reactive protein (CRP), and fasting blood glucose levels. Smoking and drinking status of the participants were often missing in the records, and were not used for data analysis.

Chest CT was performed without enhancement using an Aquilion 64 scanner (Toshiba Medical System, Japan). Slice thickness was $5 \mathrm{~mm}$, and was observed from the mediastinal window. Epicardial fat thickness was measured on the middle slice by counting the number of slices from the slice where the right ventricle first began to be visible to the last observed slice. A vertical line was drawn from the straight line connecting the right and left atrio-ventricular grooves to the apex of the right ventricle, and then a vertical line bisecting the line was drawn to measure adipose tissue thickness from the point of contact with the free wall of the right ventricle to the pericardium. The epicardial adipose tissue thickness was measured two times on different days by one observer, and the mean value of two measurements was used for data analysis.

\subsection{Statistical Analysis}

The participants were divided by gender, and differences in the evaluated parameters are expressed as mean \pm standard deviation. Each variable was compared using the t-test. One-way ANOVA was performed by dividing epicardial adipose tissue thickness into quartiles in order to examine the difference in variables according to the increase in epicardial adipose tissue thickness. Correlation between epicardial adipose tissue thickness and cardiovascular risk variables by gender was analyzed using Spearman correlation coefficients. Multiple regression analysis was performed to identify factors independently affecting epicardial adipose tissue thickness using the variables identified. All analyses were performed using SAS software program. Statistical significance was set at $p<0.05$.

\section{Results}

\subsection{Clinical Characteristics of the Participants}

The mean age of the participants was 51.29 years old. The study population consisted of 371 men (79\%) and 98 women (21\%). Mean BMI was $24.62 \mathrm{~kg} / \mathrm{m}^{2}$, and the mean epicardial adipose tissue thickness was $2.47 \mathrm{~mm}$. BMI, systolic and diastolic blood pressure, white blood cell count, and triglycerides were higher in male participants than in female participants, whereas CRP and mean epicardial adipose tissue thickness were higher in female participants (Table 1).

\subsection{Comparison of Variables According to Epicardial Adipose Tissue Thickness}

The epicardial adipose tissue thickness of all participants was divided by quartiles, 
Table 1. Baseline characteristics of subjects.*

\begin{tabular}{ccccc}
\hline & Total $(\mathrm{n}=469)$ & Men $(\mathrm{n}=371)$ & Women $(\mathrm{n}=98)$ & $P$-value ${ }^{\dagger}$ \\
\hline Age $($ years $)$ & $51.29 \pm 6.91$ & $51.29 \pm 6.11$ & $51.32 \pm 9.38$ & 0.66 \\
Height $(\mathrm{cm})$ & $167.21 \pm 7.79$ & $169.94 \pm 5.55$ & $156.84 \pm 6.14$ & $<0.001$ \\
Weight $(\mathrm{kg})$ & $69.03 \pm 10.56$ & $71.67 \pm 9.45$ & $59.02 \pm 8.36$ & $<0.001$ \\
BMI $\left(\mathrm{kg} / \mathrm{m}^{2}\right)$ & $24.62 \pm 2.84$ & $24.78 \pm 2.71$ & $24.00 \pm 3.22$ & 0.04 \\
Total body fat $(\%)$ & $26.05 \pm 5.19$ & $24.43 \pm 4.12$ & $32.15 \pm 4.15$ & $<0.001$ \\
SBP $(\mathrm{mmHg})$ & $114.63 \pm 12.18$ & $115.66 \pm 12.23$ & $110.71 \pm 11.24$ & 0.002 \\
DBP $(\mathrm{mmHg})$ & $75.03 \pm 9.00$ & $76.17 \pm 8.91$ & $70.71 \pm 8.03$ & $<0.001$ \\
WBC $\left(10^{3} / \mathrm{uL}\right)$ & $6.16 \pm 1.74$ & $6.30 \pm 1.72$ & $5.63 \pm 1.72$ & 0.003 \\
TC $(\mathrm{mg} / \mathrm{dL})$ & $203.22 \pm 37.60$ & $201.64 \pm 38.10$ & $209.23 \pm 35.16$ & 0.18 \\
TG $(\mathrm{mg} / \mathrm{dL})$ & $150.81 \pm 91.47$ & $159.10 \pm 96.30$ & $119.44 \pm 61.15$ & $<0.001$ \\
HDL-C $(\mathrm{mg} / \mathrm{dL})$ & $49.58 \pm 11.33$ & $48.13 \pm 10.72$ & $55.07 \pm 11.97$ & $<0.001$ \\
LDL-C $(\mathrm{mg} / \mathrm{dL})$ & $129.13 \pm 29.52$ & $128.78 \pm 29.74$ & $130.46 \pm 28.79$ & 0.81 \\
CRP $(\mathrm{mg} / \mathrm{dL})$ & $0.22 \pm 0.73$ & $0.16 \pm 0.28$ & $0.37 \pm 1.33$ & 0.02 \\
Glucose $(\mathrm{mg} / \mathrm{dL})$ & $94.62 \pm 21.88$ & $95.04 \pm 22.49$ & $93.01 \pm 19.40$ & 0.49 \\
EAT-T $(\mathrm{mm})$ & $2.47 \pm 1.64$ & $2.40 \pm 1.72$ & $2.70 \pm 1.26$ & 0.04 \\
\hline
\end{tabular}

BMI: body mass index, SBP: systolic blood pressure, DBP: diastolic blood pressure, TC: total cholesterol, TG: triglycerides, CRP: C-reactive protein, EAT-T: epicardial adipose tissue thickness. ${ }^{*}$ Data are presented as mean $\pm \mathrm{SD} .{ }^{\dagger} P$-value by t-test for sex.

and the mean values of the clinical features according to quartiles of epicardial adipose tissue thickness were compared. One-way ANOVA was used to compare the mean values of the four quartile groups. Statistically significant differences were observed in age, height, weight, BMI, body fat, systolic blood pressure, and fasting glucose according to epicardial adipose tissue thickness (Table 2).

\subsection{Association between Epicardial Adipose Tissue Thickness and Cardiovascular Risk Factors}

In men, epicardial adipose tissue thickness showed a significant positive correlation with body fat, followed by BMI, body weight, fasting blood glucose, systolic blood pressure, LDL cholesterol, age, diastolic blood pressure, and total cholesterol. In women, epicardial adipose tissue thickness positively correlated with BMI, followed by body fat, age, body weight, diastolic blood pressure, triglycerides, fasting glucose, systolic blood pressure, and CRP, and negatively correlated with height (Table 3).

\subsection{Results of Multiple Regression Analysis}

Multiple regression analysis was performed for variables that showed a significant correlation with epicardial adipose tissue thickness. Body weight and BMI in men and height, body weight, and BMI in women were factors that affected each other, and only BMI was included in the multiple regression analysis. Age, BMI, systolic pressure, and fasting blood glucose were statistically significant independent variables for epicardial adipose tissue thickness in men, whereas no statistical significance was observed for any variable in women (Table 4). 
Table 2. Comparison of variables according to EAT thickness quartile group.*

\begin{tabular}{|c|c|c|c|c|c|}
\hline & \multicolumn{4}{|c|}{ Quartiles of EAT thickness $^{\dagger}$} & \multirow{2}{*}{$P$-value } \\
\hline & 1 & 2 & 3 & 4 & \\
\hline Number & 118 & 117 & 117 & 117 & \\
\hline Age (years) & $50.14 \pm 6.02$ & $50.51 \pm 7.25$ & $51.86 \pm 6.87$ & $52.66 \pm 7.22$ & 0.02 \\
\hline Height $(\mathrm{cm})$ & $169.11 \pm 6.04$ & $166.62 \pm 8.09$ & $165.43 \pm 7.74$ & $167.65 \pm 8.66$ & 0.002 \\
\hline Weight (kg) & $68.22 \pm 9.97$ & $66.72 \pm 9.62$ & $67.77 \pm 10.47$ & $73.41 \pm 10.98$ & $<0.001$ \\
\hline BMI $\left(\mathrm{kg} / \mathrm{m}^{2}\right)$ & $23.80 \pm 2.79$ & $23.95 \pm 2.34$ & $24.70 \pm 2.99$ & $26.02 \pm 2.66$ & $<0.001$ \\
\hline Total body fat (\%) & $23.64 \pm 4.92$ & $25.78 \pm 4.41$ & $26.79 \pm 5.37$ & $28.00 \pm 5.05$ & $<0.001$ \\
\hline SBP (mmHg) & $112.29 \pm 12.50$ & $114.62 \pm 11.64$ & $114.19 \pm 12.61$ & $117.44 \pm 11.53$ & 0.01 \\
\hline $\mathrm{DBP}(\mathrm{mmHg})$ & $73.47 \pm 9.73$ & $75.56 \pm 9.04$ & $74.53 \pm 9.14$ & $76.58 \pm 7.79$ & 0.05 \\
\hline $\mathrm{WBC}\left(10^{3} / \mathrm{uL}\right)$ & $6.10 \pm 1.76$ & $6.10 \pm 1.83$ & $6.30 \pm 1.79$ & $6.14 \pm 1.56$ & 0.78 \\
\hline $\mathrm{TC}(\mathrm{mg} / \mathrm{dL})$ & $196.75 \pm 36.39$ & $202.53 \pm 34.10$ & $205.56 \pm 39.09$ & $208.11 \pm 40.05$ & 0.11 \\
\hline TG (mg/dL) & $146.08 \pm 110.25$ & $146.61 \pm 91.25$ & $159.74 \pm 90.05$ & $150.86 \pm 70.32$ & 0.64 \\
\hline HDL-C (mg/dL) & $49.08 \pm 11.92$ & $50.06 \pm 11.47$ & $49.32 \pm 11.71$ & $49.27 \pm 10.29$ & 0.95 \\
\hline LDL-C (mg/dL) & $124.08 \pm 28.37$ & $128.32 \pm 28.30$ & $130.90 \pm 29.70$ & $133.25 \pm 31.21$ & 0.10 \\
\hline CRP (mg/dL) & $0.14 \pm 0.19$ & $0.20 \pm 0.51$ & $0.22 \pm 0.61$ & $0.33 \pm 1.24$ & 0.39 \\
\hline Glucose (mg/dL) & $89.86 \pm 20.09$ & $94.46 \pm 21.10$ & $94.82 \pm 19.85$ & $99.36 \pm 25.27$ & 0.01 \\
\hline
\end{tabular}

BMI: body mass index, SBP: systolic blood pressure, DBP: diastolic blood pressure, TC: total cholesterol, TG: triglycerides, CRP: C-reactive protein, EAT: epicardial adipose tissue. ${ }^{*}$ Data are presented as mean \pm SD. ${ }^{\dagger}$ The cut points of the quartiles are 1.530, 2.370, and $3.335 \mathrm{~mm} .{ }^{*} \mathrm{P}$-values by One-way ANOVA.

Table 3. Correlation between EAT thickness and cariovascular risk factors.

\begin{tabular}{ccccc}
\hline \multirow{2}{*}{ Variables } & \multicolumn{2}{c}{ Men } & \multicolumn{2}{c}{ Women } \\
\cline { 2 - 5 } & $\mathrm{r}^{*}$ & $P$-value & $\mathrm{r}^{*}$ & $P$-value \\
\hline Age (years) & 0.129 & 0.01 & 0.324 & 0.001 \\
Height $(\mathrm{cm})$ & 0.000 & 0.10 & -0.281 & 0.005 \\
Weight $(\mathrm{kg})$ & 0.231 & $<0.001$ & 0.311 & 0.002 \\
BMI $\left(\mathrm{kg} / \mathrm{m}^{2}\right)$ & 0.265 & $<0.001$ & 0.471 & $<0.001$ \\
Total body fat $(\%)$ & 0.296 & $<0.001$ & 0.459 & $<0.001$ \\
SBP $(\mathrm{mmHg})$ & 0.158 & 0.002 & 0.231 & 0.02 \\
DBP $(\mathrm{mmHg})$ & 0.123 & 0.02 & 0.290 & 0.004 \\
WBC $\left(10^{3} / \mathrm{uL}\right)$ & 0.059 & 0.26 & 0.116 & 0.26 \\
TC $(\mathrm{mg} / \mathrm{dL})$ & 0.117 & 0.02 & 0.097 & 0.34 \\
TG $(\mathrm{mg} / \mathrm{dL})$ & 0.102 & 0.05 & 0.262 & 0.009 \\
HDL-C $(\mathrm{mg} / \mathrm{dL})$ & -0.014 & 0.79 & -0.121 & 0.23 \\
LDL-C $(\mathrm{mg} / \mathrm{dL})$ & 0.136 & 0.009 & 0.116 & 0.25 \\
CRP $(\mathrm{mg} / \mathrm{dL})$ & 0.043 & 0.51 & 0.210 & 0.04 \\
Glucose $(\mathrm{mg} / \mathrm{dL})$ & 0.204 & $<0.001$ & 0.246 & 0.02 \\
\hline
\end{tabular}

EAT: epicardial adipose tissue. BMI: body mass index, SBP: systolic blood pressure, DBP: diastolic blood pressure, TC: total cholesterol, TG: triglycerides, CRP: C-reactive protein, ${ }^{*} \mathrm{r}$ : Spearman's correlation coefficient. 
Table 4. Multiple linear regression analysis between EAT thickness and cardiovascular risk facors.

\begin{tabular}{ccccc}
\hline \multirow{2}{*}{ Variables } & \multicolumn{2}{c}{ Men $^{*}$} & \multicolumn{2}{c}{ Women $^{*}$} \\
\cline { 2 - 5 } & $\mathrm{B}^{\dagger} \pm \mathrm{SE}$ & $P$-value & $\mathrm{B}^{\dagger} \pm \mathrm{SE}$ & $P$-value \\
\hline Age (years) & $0.030 \pm 0.014$ & 0.03 & $0.025 \pm 0.015$ & 0.11 \\
BMI (kg/m²) & $0.137 \pm 0.050$ & 0.01 & $0.111 \pm 0.069$ & 0.11 \\
Total body fat $(\%)$ & $0.045 \pm 0.033$ & 0.18 & $0.044 \pm 0.056$ & 0.43 \\
SBP (mmHg) & $0.026 \pm 0.012$ & 0.03 & $-0.019 \pm 0.020$ & 0.32 \\
DBP (mmHg) & $-0.027 \pm 0.016$ & 0.10 & $0.025 \pm 0.027$ & 0.36 \\
TC (mg/dL) & $0.000 \pm 0.008$ & 0.98 & & 0.60 \\
TG (mg/dL) & & & $0.001 \pm 0.002$ & \\
LDL-C (mg/dL) & $0.006 \pm 0.010$ & 0.50 & & 0.85 \\
CRP (mg/dL) & & & $0.017 \pm 0.090$ & 0.45 \\
Glucose (mg/dL) & $0.009 \pm 0.004$ & 0.02 & $0.006 \pm 0.007$ & \\
\hline
\end{tabular}

EAT: epicardial adipose tissue, BMI: body mass index, SBP: systolic blood pressure, DBP: diastolic blood pressure, TC: total cholesterol, TG: triglycerides, CRP: C-reactive protein, SE: standard errors. ${ }^{*}$ The independent variables in men are age, BMI, total body fat, systolic blood pressure, diastolic blood pressure, total cholesterol, LDL-C, glucose and the independent variables in women are age, BMI, total body fat, systolic blood pressure, diastolic blood pressure, triglycerides, CRP, glucose. The dependent variable is the EAT thickness. ${ }^{\dagger}$ Coefficients (B) and P-values are calculated by entered method in multiple linear regression analysis. The $\mathrm{R}^{2}$ of men is $16.2 \%$ and the $\mathrm{R}^{2}$ of women is $30.9 \%$.

\section{Discussion}

The results of the present study show that the epicardial adipose tissue thickness measured with chest CT in healthy individuals correlates with cardiovascular risk factors in men. It has been reported that obesity is a risk factor for cardiovascular disease, metabolic syndrome, and mortality, and that body fat distribution was more closely associated with health risk than the amount of total body fat [10]. In particular, increased visceral fat mass may increase the risk of cardiovascular disease and metabolic syndrome regardless of body weight [11] [12]. However, most studies on visceral fat have been limited to abdominal fat.

As it has recently been reported that epicardial adipose tissue fat is strongly associated with cardiovascular disease and metabolic syndrome, there is growing interest in epicardial adipose tissue as a new indicator of visceral fat. Concerning the mechanism by which epicardial adipose tissue affects cardiovascular disease or metabolic syndrome, it has been hypothesized that epicardial adipose tissue may act as the source of various cytokines that cause inflammation and atherosclerosis [13] [14]. In addition, it is also argued that epicardial adipose tissue may have greater effects on coronary artery disease than abdominal visceral fat due to the local effect of epicardial adipose tissue, which directly surrounds the coronary arteries [15].

In related studies conducted to date, the measurement of epicardial adipose tissue mainly included measurement of adipose tissue thickness by transthoracic echocardiography and adipose tissue thickness, area, or total volume by 3-D 
cardiac CT. Previous studies using transthoracic echocardiography showed that epicardial adipose tissue thickness measured on the right ventricle correlated with waist circumference, abdominal visceral fat, insulin resistance, metabolic syndrome, and the severity of coronary artery disease [6] [16] [17] [18]. A number of studies using cardiac CT also showed that the amount of epicardial adipose tissue was associated with cardiovascular risk factors, coronary artery calcification, metabolic syndrome, and diabetes, independent of recognized obesity-related indicators such as BMI or waist circumference [19] [20] [21] [22] [23].

Unlike most previous studies on epicardial adipose tissue using transthoracic echocardiography or cardiac CT performed in patients with metabolic disease or suspected coronary artery disease, the present study measured epicardial adipose tissue thickness using chest $\mathrm{CT}$ in healthy individuals without a history of such a disease. The results show that epicardial adipose tissue thickness correlated with age, body weight, BMI, total body fat percentage, systolic and diastolic blood pressure, and fasting blood glucose in both sexes. A significant association of epicardial adipose tissue thickness with total cholesterol and LDL cholesterol was observed in men, whereas a significant association of epicardial adipose tissue thickness with triglycerides and CRP was observed in women. Although the method for measuring epicardial adipose tissue thickness and the participants of the present study were different from previous investigations, the results of the present study are consistent with previously reported results, indicating the possibility that measurement of epicardial adipose tissue thickness could be used as a cardiovascular risk factor. In the present study, multiple regression analysis of cardiovascular disease-related variables showed that age, BMI, systolic blood pressure, and fasting blood glucose were independent variables associated with epicardial adipose tissue thickness in men, whereas no independent association was observed for any variable in women. These results might be due to the higher rates of smoking and drinking in men than women, because a history of drinking and a history of smoking were not included in the data analysis. In addition, mean total body fat percentage was higher in women than in men, but the actual amount of visceral fat was likely to be higher in men because indicators reflecting visceral fat, such as waist circumference, were not measured.

The present study is significant in that epicardial adipose tissue thickness was measured using chest $\mathrm{CT}$, which is performed at a relatively high frequency for the general population in health examinations or routine clinical practice. The measurement of epicardial adipose tissue thickness using transthoracic echocardiography has the disadvantage that epicardial adipose tissue thickness can be measured only by skilled observers, and 3-D cardiac CT is costly and is not often used for screening purposes in healthy people. In addition, the methods for measuring epicardial adipose tissue as the whole epicardial adipose tissue volume or adipose tissue area at a specific location using cardiac CT, as used in previous studies, require the reconstruction of separate radiographic images using Hounsfield numbers, and it thus seems unlikely that it can be easily used in clinical practice. 
As in most studies using transthoracic echocardiography, the present study measured epicardial adipose tissue thickness on the right ventricle free wall. This is because epicardial adipose tissue is 3 to 4 times more distributed to the right ventricle than the left ventricle, which makes it easy to measure adipose tissue thickness on the right ventricle free wall [24]. However, a study comparing epicardial adipose tissue volume, thickness, and cross-sectional area using cardiac CT showed that the method for quantifying total fat volume was highly reproducible compared to the other two measurement methods [25]. In addition, it is thought that the precision and reproducibility of images obtained with chest CT may be somewhat low compared to measurements using cardiac CT, because cardiac movement leads to reduced quality of chest CT images of structures surrounding the heart.

The present study involved healthy adults with no history of cardiovascular disease or metabolic disease, and found that epicardial adipose tissue thickness on chest CT was independently associated with cardiovascular risk factors such as age, BMI, systolic blood pressure, and fasting blood glucose in men. The results of the present analysis are significant in that previous studies using transthoracic echocardiography or cardiac CT could also be validated by measurement of epicardial adipose tissue using chest $\mathrm{CT}$ in healthy individuals.

However, the present study has limitations. Other indicators of abdominal visceral fat were not measured, smoking history and drinking history were not investigated, and the accuracy of the epicardial adipose tissue thickness measurement process using chest CT was low. It is thus necessary to conduct further studies with standardized methods to improve the accuracy of adipose tissue measurement surrounding the heart. Additionally, our study population mainly consisted of men, which may limit the generalizability of the results. Clinical studies including healthy people without a history of cardiovascular or chronic disease should be performed to evaluate the possibility that epicardial adipose tissue can be used as a risk factor to predict cardiovascular disease in the general population.

\section{Conflict of Interest}

We declare that we have no conflict of interest.

\section{References}

[1] Wilson, P.W., D’Agostino, R.B., Sullivan, L., Parise, H., Kannel Wilson, P.W., D'Agostino, R.B., Sullivan, L., Parise, H. and Kannel, W.B. (2002) Overweight and Obesity as Determinants of Cardiovascular Risk: The Framingham Experience. Archives of Internal Medicine, 162, 1867-1872.

https://doi.org/10.1001/archinte.162.16.1867

[2] Albu, J.B., Kovera, A.J. and Johnson, J.A. (2000) Fat Distribution and Health in Obesity. Annals of the New York Academy of Sciences, 904, 491-501. https://doi.org/10.1111/j.1749-6632.2000.tb06505.x

[3] Molenaar, E.A., Hwang, S.J., Vasan, R.S., Grobbee, D.E., Meigs, J.B., D’Agostino, 
R.B., et al. (2008) Burden and Rates of Treatment and Control of Cardiovascular Disease Risk Factors in Obesity: The Framingham Heart Study. Diabetes Care, 31, 1367-1372. https://doi.org/10.2337/dc07-2413

[4] Shimabukuro, M. (2009) Cardiac Adiposity and Global Cardiometabolic Risk: New Concept and Clinical Implication. Circulation Journal, 73, 27-34.

https://doi.org/10.1253/circj.CJ-08-1012

[5] Björntorp, P. (1990) "Portal" Adipose Tissue as a Generator of Risk Factors for Cardiovascular Disease and Diabetes. Arteriosclerosis, 10, 493-496. https://doi.org/10.1161/01.ATV.10.4.493

[6] Iacobellis, G., Assael, F., Ribaudo, M.C., Zappaterreno, A., Alessi, G., Di Mario, U., et al. (2003) Epicardial Fat from Echocardiography: A New Method for Visceral Adipose Tissue Prediction. Obesity, 11, 304-310.

https://doi.org/10.1038/oby.2003.45

[7] Bertaso, A.G., Bertol, D., Duncan, B.B. and Foppa, M. (2013) Epicardial Fat: Definition, Measurements and Systematic Review of Main Outcomes. Arquivos Brasileiros De Cardiologia, 101, e18-e28.

[8] Sarin, S., Wenger, C., Marwaha, A., Qureshi, A., Go, B.D., Woomert, C.A., et al. (2008) Clinical Significance of Epicardial Fat Measured Using Cardiac Multislice Computed Tomography. American Journal of Cardiology, 102, 767-771. https://doi.org/10.1016/j.amjcard.2008.04.058

[9] Meenakshi, K., Rajendran, M., Srikumar, S. and Chidambaram, S. (2016) Epicardial Fat Thickness: A Surrogate Marker of Coronary Artery Disease-Assessment by Echocardiography. Indian Heart Journal, 68, 336-341. https://doi.org/10.1016/j.ihj.2015.08.005

[10] Després, J.P., Lemieux, I. and Prud'homme, D. (2001) Treatment of Obesity: Need to Focus on High Risk Abdominally Obese Patients. BMJ, 322, 716-720. https://doi.org/10.1136/bmj.322.7288.716

[11] Després, J.P. (2006) Is Visceral Obesity the Cause of the Metabolic Syndrome? Annals of Medicine, 38, 52-63. https://doi.org/10.1080/07853890500383895

[12] Carr, D.B., Utzschneider, K.M., Hull, R.L., Kodama, K., Retzlaff, B.M., Brunzell, J.D., et al. (2004) Intra-Abdominal Fat Is a Major Determinant of the National Cholesterol Education Program Adult Treatment Panel III Criteria for the Metabolic Syndrome. Diabetes, 53, 2087-2094. https://doi.org/10.2337/diabetes.53.8.2087

[13] Mazurek, T., Zhang, L., Zalewski, A., Mannion, J.D., Diehl, J.T., Arafat, H., et al. (2003) Human Epicardial Adipose Tissue Is a Source of Inflammatory Mediators. Circulation, 108, 2460-2466. https://doi.org/10.1161/01.CIR.0000099542.57313.C5

[14] Baker, A.R., Silva, N.F., Quinn, D.W., Harte, A.L., Pagano, D., Bonser, R.S., et al. (2006) Human Epicardial Adipose Tissue Expresses a Pathogenic Profile of Adipocytokines in Patients with Cardiovascular Disease. Cardiovascular Diabetology, 5, 1-8. https://doi.org/10.1186/1475-2840-5-1

[15] Yong, H.S., Kim, E.J., Seo, H.S., Kang, E.Y., Kim, Y.K., Woo, O.H., et al. (2010) Pericardial Fat Is More Abundant in Patients with Coronary Atherosclerosis and Even in the Non-Obese Patients: Evaluation with Cardiac CT Angiography. The International Journal of Cardiovascular Imaging, 26, 53-62. https://doi.org/10.1007/s10554-009-9542-2

[16] Jeong, J.W., Jeong, M.H., Yun, K.H., Oh, S.K., Park, E.M., Kim, Y.K., et al. (2007) Echocardiographic Epicardial Fat Thickness and Coronary Artery Disease. Circulation Journal, 71, 536-539. https://doi.org/10.1253/circj.71.536 
[17] Ahn, S.G., Lim, H.S., Joe, D.Y., Kang, S.J., Choi, B.J., Choi, S.Y., et al. (2008) Relationship of Epicardial Adipose Tissue by Echocardiography to Coronary Artery Disease. Heart, 94, e7. https://doi.org/10.1136/hrt.2007.118471

[18] Iacobellis, G., Ribaudo, M.C., Assael, F., Vecci, E., Tiberti, C., Zappaterreno, A., et al. (2003) Echocardiographic Epicardial Adipose Tissue Is Related to Anthropometric and Clinical Parameters of Metabolic Syndrome: A New Indicator of Cardiovascular Risk. The Journal of Clinical Endocrinology \& Metabolism, 88, 5163-5168. https://doi.org/10.1210/jc.2003-030698

[19] Wheeler, G.L., Shi, R., Beck, S.R., Langefeld, C.D., Lenchik, L., Wagenknecht, L.E., et al. (2005) Pericardial and Visceral Adipose Tissues Measured Volumetrically with Computed Tomography Are Highly Associated in Type 2 Diabetic Families. Investigative Radiology, 40, 97-101. https://doi.org/10.1097/00004424-200502000-00007

[20] Silaghi, A., Piercecchi-Marti, M.D., Grino, M., Leonetti, G., Alessi, M.C., Clement, K., et al. (2008) Epicardial Adipose Tissue Extent: Relationship with Age, Body Fat Distribution, and Coronaropathy. Obesity (Silver Spring), 16, 2424-2430. https://doi.org/10.1038/oby.2008.379

[21] Gorter, P.M., de Vos, A.M., van der Graaf, Y., Stella, P.R., Doevendans, P.A., Meijs, M.F., et al. (2008) Relation of Epicardial and Pericoronary Fat to Coronary Atherosclerosis and Coronary Artery Calcium in Patients Undergoing Coronary Angiography. American Journal of Cardiology, 102, 380-385.

https://doi.org/10.1016/j.amjcard.2008.04.002

[22] deVos, A.M., Prokop, M., Roos, C.J., Meijs, M.F., van der Schouw, Y.T., Rutten, A., et al. (2008) Peri-Coronary Epicardial Adipose Tissue Is Related to Cardiovascular Risk Factors and Coronary Artery Calcification in Post-Menopausal Women. European Heart Journal, 29, 777-783. https://doi.org/10.1093/eurheartj/ehm564

[23] Wang, C.P., Hsu, H.L., Hung, W.C., Yu, T.H., Chen, Y.H., Chiu, C.A., et al. (2009) Increased Epicardial Adipose Tissue (EAT) Volume in Type 2 Diabetes Mellitus and Association with Metabolic Syndrome and Severity of Coronary Atherosclerosis. Clinical Endocrinology $(O x f), 70,876-882$. https://doi.org/10.1111/j.1365-2265.2008.03411.x

[24] Rabkin, S.W. (2007) Epicardial Fat: Properties, Function and Relationship to Obesity. Obesity Reviews, 8, 253-261. https://doi.org/10.1111/j.1467-789X.2006.00293.x

[25] Gorter, P.M., van Lindert, A.S., de Vos, A.M., Meijs, M.F., van der Graaf, Y., Doevendans, P.A., et al. (2008) Quantification of Epicardial and Peri-Coronary Fat Using Cardiac Computed Tomography; Reproducibility and Relation with Obesity and Metabolic Syndrome in Patients Suspected of Coronary Artery Disease. Atherosclerosis, 197, 896-903. https://doi.org/10.1016/j.atherosclerosis.2007.08.016 